\title{
The Evaluation of Children's Walking to and from School Safety: A Case Study in Wuhan
}

\author{
Jie Shen \\ School of Urban Construction \\ Wuhan University of Science and Technology \\ Wuhan, Hubei, China \\ shenjie@wust.edu.cn
}

\author{
Shanlai Zou, Chen Liang \\ School of Urban Construction \\ Wuhan University of Science and Technology \\ Wuhan, Hubei, China
}

\begin{abstract}
In recent years, the number of motor vehicles and the total mileage of roads have been increasing, which leads to traffic accidents occur frequently. Children are the most vulnerable group, so improving the safety of walking to and from school has become very urgent in urban development. Based on the analysis of domestic and foreign literature, this paper puts forwards three dimensions of evaluation index system of environment, facilities and management and evaluates the streets around two primary schools in Wuhan. The results show that the traffic volume, the vehicle speed, the occupation of sidewalk and the vehicle avoidance are the most important indicators that need to be improved.
\end{abstract}

Keywords-children's transportation to and from school; walking; safety; streets; evaluation

\section{ESTABLISHMENT OF WALKING SAFETY EVALUATION SYSTEM}

The latest Survey of the World Health Organization shows that, more than 110,000 children and adolescents died of road traffic injuries in 2015, and a large part of them occurred during walking and cycling [1]. The "Two Point One Line" constructed by "Home-Street-School" is inevitable and the most important space contact opportunity between children and cities. As one of the most important places for children's daily activities, there exist unsafe factors in school streets that will undoubtedly have an impact on children's walking.
The research on safety of walking abroad is more in-depth, but late in China. The study selected the SCIE, SSCI 3 and above and the Chinese core journals as the basis for the literature review. Through the domestic and international literature review to extract relevant indicators, it is found that the selection indicators are miscellaneous, and the walking safety at the street level is not targeted. Therefore, the research group summarizes and refines the initially determined indicators through multiple internal discussions, invites experts from urban planning and management departments, design units and scientific research institutions of colleges and universities to carry out opinion surveys, taking into account comprehensively the principles of typicality, perceptibility, measurability of walking safety indicators and implementability of street reconstruction. Then use Delphi method to further screen the indexes. Finally determine the 22 indicators of environment, facilities, management of the three dimensions and construct walking safety evaluation index system. Invite experts to judge the importance of each index in pair-wise comparison, and measure the ratio of relative importance of each index is by rank 1-9. With the help of the analytic hierarchy process software, sort out the importance comparison results of each expert, and construct the judgment matrix of pairwise comparison from the criterion layer, then normalize the judgment matrix to verify the consistency, to obtain the weight of each index element (TABLE I).

TABLE I. WALKING SAFETy EVALUATION INDEX SySTEM AND WEIGHT

\begin{tabular}{|c|c|c|c|c|c|c|}
\hline Rule layer & Weight & Element layer & Weight & Index layer & Weight & Correlation \\
\hline \multirow{5}{*}{ Traffic environment } & \multirow{5}{*}{0.268} & \multirow{4}{*}{ Motor vehicle traffic } & \multirow{4}{*}{0.247} & Traffic flow & 0.082 & negative \\
\hline & & & & Motor vehicle speed & 0.106 & negative \\
\hline & & & & Roadside parking density & 0.039 & negative \\
\hline & & & & Heavy vehicle ratio & 0.021 & negative \\
\hline & & Road design & 0.021 & Intersection density & 0.021 & positive \\
\hline \multirow{12}{*}{$\begin{array}{l}\text { Traffic } \\
\text { facility }\end{array}$} & \multirow{12}{*}{0.503} & \multirow{5}{*}{ Sidewalk } & \multirow{5}{*}{0.275} & Sidewalk occupancy & 0.072 & negative \\
\hline & & & & Pavement integrity & 0.027 & positive \\
\hline & & & & Sidewalk width & 0.085 & positive \\
\hline & & & & Pedestrian congestion & 0.056 & negative \\
\hline & & & & Pavement continuity & 0.034 & positive \\
\hline & & \multirow{7}{*}{ Road facility } & \multirow{7}{*}{0.228} & Integrity of traffic lights & 0.050 & positive \\
\hline & & & & Integrity of traffic lines & 0.021 & positive \\
\hline & & & & Integrity of traffic signs & 0.012 & positive \\
\hline & & & & Speed belt integrity & 0.016 & positive \\
\hline & & & & Safety barrier integrity & 0.036 & positive \\
\hline & & & & Integrity of three-dimensional crossing facilities & 0.025 & positive \\
\hline & & & & The rationality of green time for crossing the street & 0.049 & positive \\
\hline
\end{tabular}

1 Hubei Provincial Department of Education, Philosophy and Social Science Research Youth Project (19Q023)

2 Wuhan University of Science and Technology College Students Innovation and Entrepreneurship Training Program (18ZRA020) 


\begin{tabular}{|c|c|c|c|c|c|c|}
\hline \multicolumn{7}{|c|}{ Cont. to TABLE I. } \\
\hline \multirow{5}{*}{ Traffic management } & \multirow{5}{*}{0.229} & \multirow{2}{*}{ Traffic enforcement measures } & \multirow{2}{*}{0.056} & Traffic police on duty & 0.033 & positive \\
\hline & & & & Traffic warden on duty & 0.023 & positive \\
\hline & & \multirow{3}{*}{ Driving behavior } & \multirow{3}{*}{0.173} & Vehicle running through a red light & 0.060 & negative \\
\hline & & & & Motor vehicle transfer & 0.068 & negative \\
\hline & & & & Motor vehicle steering in violation of regulations & 0.063 & negative \\
\hline Sum & 1.000 & & 1.000 & & 1.000 & \\
\hline
\end{tabular}

\section{THE EVALUATION OF CHILDREN'S WALKING TO AND FROM} SCHOOL SAFETY

\section{A. Evaluation object and evaluation method design}

This paper selects Wuhan Primary School and Fujiapo Primary School in Wuchang District of Wuhan City and its surrounding blocks as the research sites. Taking school as the starting point and living place as the destination, choose six streets with moderate distance, heavy traffic and low repetition as the research object (Fig. 1.). Use questionnaire survey to ask the respondents to choose the performance level of the whole street and various indicators (Level 1-5, very unsafe - very safe ).

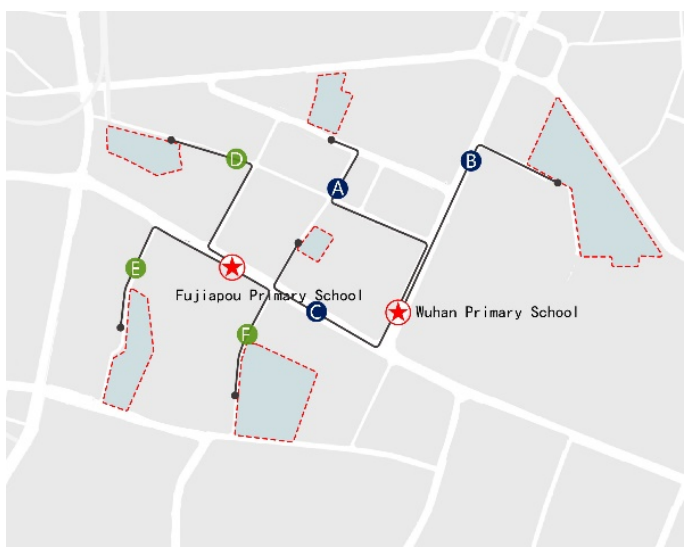

Fig. 1. Distribution of survey street

In view of the fact that in the evaluation of the pedestrian safety of the street, the adopted problem has a strong subjective sense, therefore introduce the fuzzy comprehensive evaluation method to evaluate the safety of each street[2]. Transform the existing index system into the evaluation factor set, count the average score of each index, construct the weighted average comprehensive evaluation model by the weight of each index, and the calculate fuzzy comprehensive evaluation result of each street. The results can be used as the basis for the evaluation and analysis of pedestrian safety.

\section{B. Street walking safety evaluation}

Use The fuzzy comprehensive evaluation method to evaluate the walking safety of each street. The concrete steps are as follows: transform the index system into the evaluation factor set, in which the criterion layer corresponds to the first class index, the element layer corresponds to the second class index, and the index layer corresponds to the third grade index. The performance levels of the indicators (measured in the form of the Likert scale, $\mathrm{V}=$ [very unsafe, generally safe and safe]) were transformed into the corresponding fuzzy scores (statistics in the form of scores). $V^{\prime}=$ [12345], then count the average score of 22 indexes in 6 streets, and list all the scores in the form of comprehensive judgment matrix $\mathrm{D}$ :

$\mathrm{D}=\left[\begin{array}{cccc}\text { A Street } & \text { B Street } & \ldots & \text { F Street } \\ \mathrm{d}_{1,1} & \mathrm{~d}_{1,2} & \ldots & \mathrm{d}_{1,6} \\ \mathrm{~d}_{2,1} & \mathrm{~d}_{2,2} & \ldots & \mathrm{d}_{2,6} \\ \ldots & \ldots & \ldots & \ldots \\ \mathrm{d}_{22,1} & \mathrm{~d}_{22,2} & \ldots & \mathrm{d}_{22,6}\end{array}\right]=\left[\begin{array}{cccc}\text { A Street } & \text { B Street } & \ldots & \text { F Street } \\ 4.50 & 2.95 & \ldots & 3.90 \\ 2.80 & 2.90 & \ldots & 3.70 \\ \ldots & \ldots & \ldots & \ldots \\ 2.70 & 3.45 & \ldots & 3.65\end{array}\right]$

In the formula, $\mathrm{d}_{\mathrm{i}, \mathrm{j}}$ denotes the average score of the $\mathrm{i}$ index of the $\mathrm{j}$ street; $\mathrm{i}=1,2,3,22$, representing 22 indexes; $\mathrm{j}=1,2,3$, 6 , representing 6 streets.

Calculate the weight of the statistical indicator layer and establish a fuzzy vector $\mathrm{A}=\left[\begin{array}{lllll}0.082 & 0.106 & 0.039 & 0.021 & 0.021\end{array}\right.$ $\begin{array}{lllllllllll}0.021 & 0.027 & 0.085 & 0.056 & 0.034 & 0.068 & 0.021 & 0.012 & 0.016 & 0.036\end{array}$ 0.0250 .0490 .0330 .0230 .0600 .0500 .063 . When the fuzzy vector $\mathrm{A}$ and the comprehensive judgement matrix $\mathrm{D}$ are known, construct the weighted average type comprehensive evaluation model $\mathrm{M}$ by the linear transformation.

$$
M=\left(b_{1}, b_{2}, \ldots, b_{6}\right)=\left(\sum_{i=1}^{22} a_{i} \times d_{i, 1}, \sum_{i=1}^{22} a_{i} \times d_{i, 2}, \ldots, \sum_{i=1}^{22} a_{i} \times d_{i, 6}\right)
$$

In the formula, $b_{n}$ denotes the $n$th street factor, $a_{i}$ represents the weight of the index $\mathrm{i}$, and $\mathrm{d}_{\mathrm{i}, \mathrm{j}}$ represents the average score of the index $i$ of the $j$ street.

Obtain the fuzzy comprehensive evaluation set from operating the above determined comprehensive evaluation matrix D and fuzzy vector A. Calculate the score of each factor in the fuzzy comprehensive evaluation set, which is the fuzzy comprehensive score of each street (TABLE II).

TABLE II. FUZZY COMPREHENSIVE SCORE OF EACH STREET

\begin{tabular}{|c|c|c|c|c|c|c|}
\hline No. & A & B & C & D & E & F \\
\hline Fuzzy score & 3.277 & 3.194 & 3.734 & 3.333 & 2.623 & 3.525 \\
\hline Sequence & 4 & 5 & 1 & 3 & 6 & 2 \\
\hline
\end{tabular}

\section{ANALYSIS OF THE SAFETY EVALUATION RESULTS OF} CHILDREN'S WALKING AND GOING TO SCHOOL

\section{A. Analysis of evaluation results}

The results of fuzzy comprehensive evaluation show that the scores of walking safety in $\mathrm{C}$ street and $\mathrm{F}$ street are higher, that in D street and A street are in the middle, and that in $\mathrm{B}$ street and E street are lower. The overall evaluation results of the streets in the questionnaire were quantified as scores (1-5 Score) and then averaged. The results were basically consistent with the results of fuzzy comprehensive evaluation (Fig. 2.). To a certain extent, it shows that the evaluation index system and method are reasonable and accurate, which can provide a reference for the evaluation of street walking safety. 


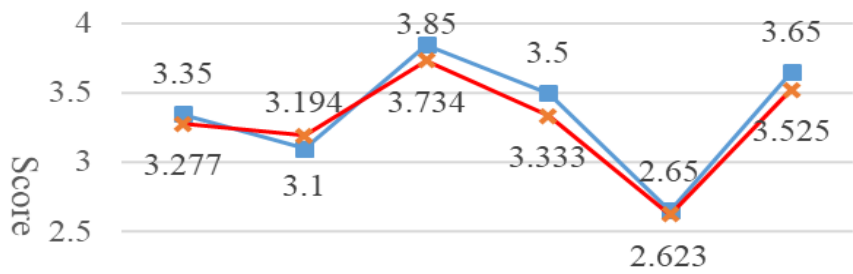

2

A Street B Street C Street D Street E Street F Street

\section{$\longrightarrow$ Street Overall Score $\longrightarrow$ - Fuzzy Score}

Fig. 2. Comparison of street overall score and fuzzy score

In order to reveal the indexes that need to be improved at present, average the index scores of the six streets in the fuzzy comprehensive evaluation as the overall performance scores of each indicator in the surrounding environment of the primary school; standardize the weights of the indicators by the analytic hierarchy process, and the standard values obtained can reflect the importance score of each indicator. Mark the expressiveness score and the importance score in the same twodimensional coordinate system, thus reflecting the difference between the actual performance of the evaluation index and the ideal target (Fig.3.)[3]. The index of I quadrant performs well in the street and the important degree is high, which is the advantage at present. It can be maintained and strengthened continuously. The index of II quadrant performs well while the important degree is low, it can be maintained in a short time. The index of III quadrant is poorly performing and the degree of importance is also low. The index of IV quadrant can be improved gradually in the future. The index of IV quadrant is poor but heavy, the traffic flow, the speed of the motor vehicle, the occupation of the sidewalk, and the passing of the motor vehicle are the contents that need to be improved at present.

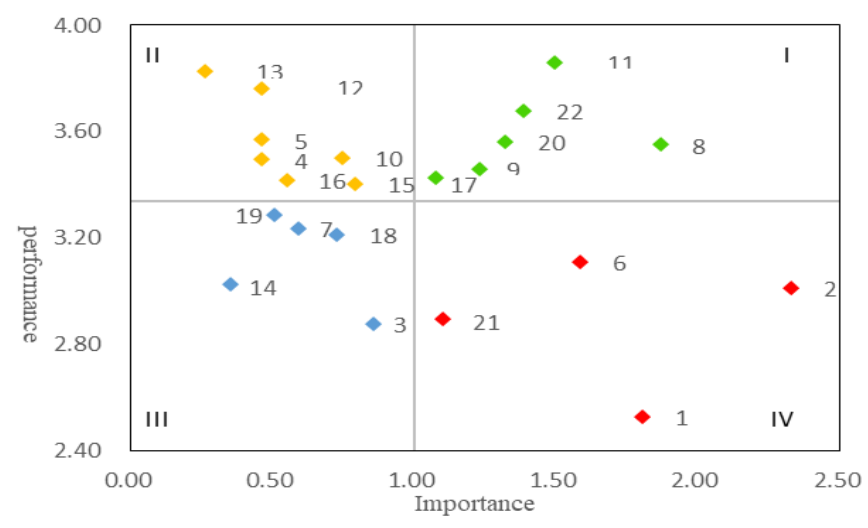

Fig. 3. Comparison of street overall score and fuzzy score

\section{B. Analysis of evaluation indicators}

According to the distribution of indicators in the two dimensional coordinate system of expressiveness--importance, we find that the traffic flow, the speed of road motor vehicles, the sidewalk occupied, and motor vehicle transfer are the contents that need to be improved urgently in the surrounding streets of two primary schools in Wuhan at present. Through the analysis of four indicators, we can see that the performance of six streets on different indexes has their own merits and demerits. This is also the result of the influence of such factors as street traffic situation, sidewalk environment difference, lack of traffic management, etc.

1) Traffic flow: F street score was the highest (3.35), A street score was the lowest (1.70). F street belongs to urban secondary trunk road, except commuting rush hour the traffic flow in the street is small; A street belongs to the main road of the city, and several design units and residential areas are distributed around it. There are often public or private cars in and out of the street, and the traffic flow in the street is large, which results in a marked score lower than that in the F street.

2) Motor vehicle speed: D street score is the highest (3.70), A street score is the lowest (2.30). D street belongs to the urban branch road, the road width is narrow, the motor vehicle travel speed in the street is slow; A street belongs to the main road of city, the motor vehicle travels fast in the street. Because the children will play around in the street at will, the traffic safety consciousness is indifferent[4], A street motor vehicle speed is fast, along the street trees, billboards and shop signs can block the sight of children and drivers, which all will pose a threat to child safety and making them significantly lower than D streets.

3) Sidewalk occupancy: C street has the highest score (4.00), E street score is the lowest (2.35). C street belongs to the main road of the city, the sidewalk width is more than six meters, the walking space is abundant, the street management is strict and sidewalk occupied is less. The E street belongs to the urban branch road, the sidewalk width is about two meters, the majority is occupied by the vehicle parking, children basically walks in the driveway. Thus the conflict between person and the vehicle is very easily produces. And the situation of sidewalk occupied is most seriously.

4) Motor vehicle transfer: D street score is the highest (3.15), B street score is the lowest (2.70). D street has open vision, sidewalk periphery has prompt sign. The motor vehicle can find the children who will cross the street in time, take corresponding measures of deceleration or detour. At the time of the investigation, there are construction sites around the $\mathrm{B}$ Street. Most children walk directly in the driveway. The number of times that vehicles need to slow down and avoid them increased significantly. In addition, the narrow width of the street, the heavy traffic and the difficulty of completing the emergency stop of the motor vehicle, change of track or other means of avoidance and so on result in a score lower than D street.

In order to determine the priority of the improvement, the importance of the above indexes is ranked, in which the speed ranking of the motor vehicle is the first, the traffic flow is the second, the sidewalk occupied is the third and the motor vehicle transfer is the fourth (Fig. 4). It is worth noting that-according to the importance of 22 indexes--sidewalk width is one of the most important indexes for children's walking safety [4-5], but not the key improvement index in this study. The direct reason is that the performance score of the sidewalk width is higher than the average and located in the good performance (I quadrant) area. However, the underlying reason is that the objective data on the width of the sidewalk was not 
included in the evaluation, just according to the subjective judgment of the interviewees. Some studies have pointed out that the width of the sidewalk in the children's active area should be kept above three meters, and the minimum is not less than two meters[6]. In the actual investigation, it is found that besides the urban main roads, the sidewalk width of most streets is less than three meters, which indicates that the performance score obtained by subjective judgment can't accurately reflect the actual situation of street environment, and the measurement of objective environment should be considered in the future evaluation research.

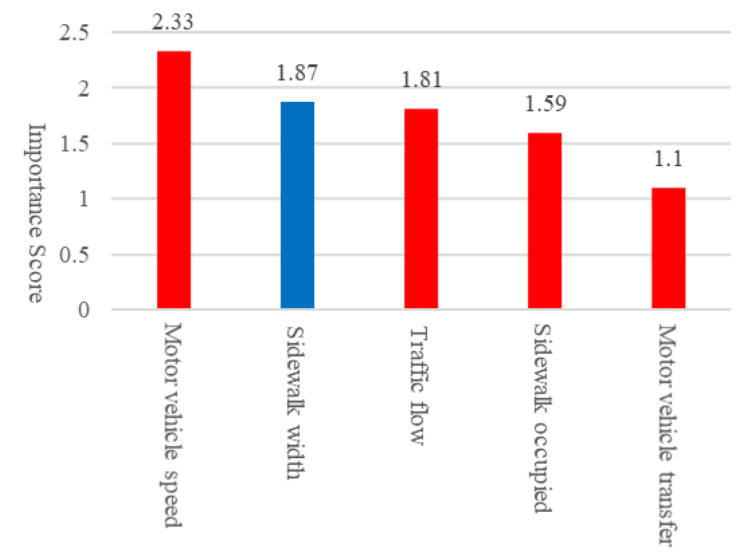

Fig. 4. Ranking of the importance of some indicators

\section{CONCLUSION}

This study, through the evaluation of the school streets around the two primary schools in Wuhan, found that traffic flow, motor vehicle speed, sidewalk occupancy, motor vehicle transfer need to be improved at present. A safe walkway road network is formed to meet the needs of vulnerable groups such as children and the elderly. Due to the limitation of evaluation objects and methods, the study has no complete coverage of the streets around primary schools in the suburbs of the city, and is lack of the quantitative data of objective physical environment; the results obtained are still preliminary. And the safety evaluation system of walking will continue to be improved in the future--expanding the research sample and optimizing the evaluation method--to provide theoretical support for the formulation of child-friendly city policy in China.

\section{REFERENCES}

[1] ORGANIZATION W H. Global accelerated action for the health of adolescents (AA-HA!): guidance to support country implementation[M]. World Health Organization, 2017.

[2] Shiyong Dong, Chenyin Long. Research on the Measurement method and Development Strategy of Walk ability of Residential District based on Fuzzy Comprehensive Evaluation: a case study of typical Residential District in Chongqing [J]. Journal of Western Human Settlements, 2015 (1): 106-112..

[3] Jusheng Song, Yi Sun, Xiaochong Hou.Analysis of spatial environmental characteristics of community parks in high-density urban areas based on the classification of activities of the elderly [J]. Journal of Architecture, 2017 (05): 116-120.

[4] Yuefang Zhou, Xi Lu, Chunyan Luo. Analysis on walking safety of primary and middle school students in Shanghai [J]. School Health in China, 2011C 32 (12): 1461-1464.

[5] Yuu-hee Tsai. Study on the Establishment of Environmental Safety Assessment Index for Primary School students on foot [D]. Chung Hua University, 2013.

[6] M Obereth Finkel, Weiqiong Wu. Activity venue: city-Design Open Space for Children friendly City [J]. Chinese Gardens, 2008 (09): 49-55. 